\title{
SIMULASI PROSES PRODUKSI LAYOUT LANTAI PRODUKSI PIPA BAJA LAS SPIRAL AWWA C200 DI PT KHI PIPE INDUSTRIES
}

\author{
Dyah Lintang Trenggonowati \\ Jurusan Teknik Industri, Fakultas Teknik, Universitas Sultan Ageng Tirtayasa, Cilegon, Indonesia \\ e-mail: dyahlintang@untirta.ac.id
}

\begin{abstract}
ABSTRAK
PT. KHI Pipe Industries merupakan salah satu perusahaan manufaktur dari anak PT. Krakatau Steel yang memproduksi pipa baja. Perusahaan ini belum mampu untuk memenuhi target produksi yang telah ditetapkan oleh perusahaan. Hal tersebut diidentifikasi terjadi bottleneck pada beberapa section pada mesin SPM 2000 yang menyebabkan jumlah produk work in procces bertambah dan jumlah produk pipa yang dihasilkan menjadi rendah. Akibatnya produksi tidak mencapai target sehingga membuat konsumen kecewa serta menimbulkan kerugian bagi perusahaan. Karena itulah, perlu adanya identifikasi bottleneck dan upaya mengurangi mesin yang bottleneck untuk meningkatkan produktifitas pipa las spriral sehingga target produksi bisa dicapai. Pada penelitian ini, simulasi digunakan untuk menyelesaikan masalah tersebut. Penelitian ini terdapat 3 usulan perbaikan. Dari ketiga usulan perbaikan tersebut, didapatkan bahwa jumlah rata-rata produk pipa baja las spiral pada usulan perbaikan 1 sebesar 4786 unit/bulan, jumlah rata-rata produk pipa baja las spiral pada usulan perbaikan 2 sebesar 4791 unit/bulan dan jumlah rata-rata produk pipa baja las spiral pada usulan perbaikan 3 sebesar 4783 unit/bulan Berdasarkan hasil tersebut, dapat disimpulkan bahwa usulan perbaikan 2 menghasilkan jumlah rata-rata produk pipa baja las spiral optimal dibandingkan dengan usulan perbaikan lainnya dan menjadi rekomendasi terbaik untuk meningkatkan produktifitas di PT. KHI Pipe Industries.
\end{abstract}

Kata kunci: Bottleneck, Produktivitas, Simulasi.

\begin{abstract}
PT. KHI Pipe Industries is one of the manufacturing companies of PT. Krakatau Steel's subsidiary which manufactures steel pipes. This company has not been able to meet the production targets set by the company. This identified bottlenecks in several sections on the SPM 2000 machine which caused the number of work in procces products to increase and the number of pipe products produced to be low. As a result, production does not reach the target, making consumers disappointed and cause losses for the company. For this reason, it is necessary to identify bottlenecks and efforts to reduce bottlenecked machinery to increase spriral welding pipe productivity so that production targets can be achieved. In this study, simulation is used to solve this problem. This study has 3 proposed improvements. From the three proposed improvements, it was found that the average number of spiral weld steel pipe products in the proposed improvement 1 was 4786 units/month, the average number of spiral welded steel pipe products in the proposed improvement 2 was 4791 units/month and the average number spiral welded steel pipe products in the proposed improvement 3 of 4783 units/month Based on these results, it can be concluded that the proposed improvement 2 produces an average number of optimum spiral welded steel pipe products compared to other proposed improvements and is the best recommendation for increasing productivity at PT. KHI Pipe Industries.
\end{abstract}

Keywords: Bottleneck, Productivity, Simulation.

\section{PENDAHULUAN}

Seiring dengan perkembangan zaman, proses-proses yang terjadi dalam manufaktur semakin kompleks alur dan tahapannya, yaitu melalui tahapan mesin dan operasi juga harus mengikuti berbagai perencanaaan yang dilakukan dengan baik dalam setiap langkahnya. Setiap prosesnya harus memperhatikan produk yang diproduksinya sesuai dengan spesifikasi yang diinginkan konsumen serta target waktu selesainya produksi dengan tepat. Pipa baja merupakan salah satu produk manufaktur yang dalam proses produksinya melalui beberapa proses produksi. 


\section{Dyah Lintang Trenggonowati}

PT. KHI Pipe Industries merupakan salah satu perusahaan manufaktur dari anak PT. Krakatau Steel yang memproduksi pipa baja. Produk pipa baja yang dihasilkan adalah pipa baja las spiral dan longitudinal, misalnya pipa air, pipa pancang dan pipa gas. Pipa air biasanya menggunakan jenis pipa AWWA C200, Pipa pancang menggunakan jenis pipa ASTM A252 dan pipa gas menggunakan jenis pipa API 5L. Bahan baku yang digunakan untuk membuat produk pipa adalah coil HRM yang berasal dari PT. Krakatau Steel. Produk pipa diproduksi melalui beberapa tahapan proses, mulai dari persiapan coil pada stand coil sampai berubah menjadi produk pipa.

Pada proses produksi sering mengalami beberapa kendala seperti sering terjadinya bottleneck pada beberapa section pada mesin SPM 2000 di PT. KHI Pipe Industries, hal tersebut menyebabkan jumlah produk work in procces bertambah dan jumlah produk pipa yang dihasilkan menjadi rendah. Akibatnya produksi tidak mencapai target sehingga membuat konsumen kecewa serta menimbulkan kerugian bagi perusahaan.

Berdasarkan permasalahan yang dialami oleh PT. KHI Pipe Industries, akan dilakukan simulasi proses produksi pipa baja las spiral pada mesin SPM 2000 untuk mengetahui berapa waktu proses produksi yang dibutuhkan dan berapa banyak jumlah produk yang dihasilkan. Setelah dilakukan simulasi, maka dapat diketahui apakah jumlah produk yang dihasilkan mencapai target produksi tiap bulannya atau tidak dan alternatif perbaikan yang dapat dilakukan untuk proses produksi agar dapat memenuhi target jumlah produk yang dipesan oleh konsumen.

\section{METODE PENELITIAN}

Penelitian ini dilakukan di PT. KHI Pipe Industries. PT. KHI Pipe Industries salah satu anak perusahaan PT. Krakatau Steel Tbk yang bergerak dibidang manufaktur, khususnya produksi pipa baja. Perusahaan ini terletak Kota Cilegon Provinsi Banten. Penelitian ini focus pada pip alas spiral (pipa air) tipe AWWA 200 dengan menggunakan mesin SPM 200. Metode yang digunakan dalam penelitia ini yaitu model simulasi komputer dengan Sofware Pro Model 7.5.

Penelitian ini diawali dengan permasalahan target produksi yang tidak dapat dicapai oleh PT. KHI Pipe Industries sehingga tujuan perusahaan untuk meningkatkan produktivitas sulit terwujud. Untuk menyelesaikan permasalahan tersebut, peneliti mengambil beberapa data waktu proses dari setiap mesin untuk diolah dengan menggunakan uji statistiak seperti uji korelasi, scatter plot, run test, estimasi parameter dan goodness of fit. Setelah itu, model diverifikasi dan divalidasi untuk membuat model simulasi awal (konseptual). Model usulan dibuat berdasarkan output simulasi promodel. Selanjutnya model usulan tersebut dibandingkan dengan model awal (eksisting) sehingga didapatkan bahwa model usulan lebih baik dibandingkan dengan model eksisting, model usulan dapat diaplikasikan oleh perusahaan. Namun, semua itu tergantung perusahaan model usulan yang manakah yang akan diambil.

\section{MODEL KONSEPTUAL}

Peneliti mengawali penelitian dengan membuat model konseptual berdasarkan sistem nyata. Model konseptual terdiri dari problem element, sistem elemen dan system relevant. Selain itu, peneliti mengambil secara langsung waktu proses di setiap mesin untuk menunjang penelitian.

\section{Problem Element}

Berdasarkan permasalahan yang peneliti ambil, terdapat beberapa problem element yang akan dibahas untuk mengetahui gambaran secara umum langkah-langkah untuk menyelesaikan permasalahan yang terjadi. Berikut adalah yang termasuk dalam problem element: 
a. Decision Maker

Decision maker dalam permasalahan yang diteliti adalah kepala Divisi Produksi PT. KHI Pipe Industries. Kepala Divisi Produksi PT. KHI Pipe Industries yang akan mengambil suatu keputusan dalam menyelesaikan permasalahan yang terjadi.

b. The Objective

Dalam penelitian ini, simulasi bertujuan untuk meningkatkan produktivitas pipa tipe AWWA C200 (pipa air) yang menggunakan mesin SPM 2000.

c. The Performance Measure

Penelitian yang diteliti adalah produk pipa tipe AWWA C200 (pipa air) sehingga produk akhir akan diukur berdasarkan satuan unit pipa tipe AWWA C200 (pipa air).

d. Alternative Courses of Action

Peneliti mengamati proses produksi, lintasan produksi dan waktu proses produksi untuk mengetahui permasalahan yang terjadi sehingga peneliti dapat menentukan alternatif perbaikan dalam mencapai tujuan penelitian. Alternatif usulan perbaikan 1 yaitu menambahkan bevel machine dan hydrostatic test machine menjadi dua buah serta menambahkan crane sebanyak dua buah. Pada mesin SPM 2000. Alternatif usulan perbaikan 2 yaitu alternatif usulan perbaikan 1 ditambah dengan menambahkan mesin section 1 menjadi dua buah. Alternatif usulan perbaikan 3 yaitu alternatif usulan perbaikan 1 ditambah dengan menambahkan mesin section 2 menjadi dua buah.

\section{Element System}

Sistem elemen adalah suatu kesatuan yang terdiri dari komponen atau elemen (bagian-bagian dasar) yang dihubungkan bersama agar memudahkan aliran energi materi atau informasi agar tercapai suatu tujuan tertentu.

\section{a. Locations}

Beberapa lokasi yang digunakan dalam penelitian simulasi ini diantaranya Stand Coil, Mesin SPM 2000 Section 1, Mesin SPM 2000 Section 2, Mesin SPM 2000 Section 3, Mesin SPM 2000 Section 4, Beveling Machine, Mesin hydrostatic test, Stand kawat, Storage sementara, Conveyor. Conveyor berjumlah 4 yang terdiri dari conveyor 1 , conveyor 2, conveyor 3 dan conveyor 4 .

\section{b. Entities}

Beberapa entitas yang ada dalam sisitem simulasi ini diantaranya coil gulungan, coil flat, coil grove, pipa, pipa hasil pemotongan, dan pipa bevel.

\section{c. Arrivals}

Dalam penelitian simulasi ini, yang termasuk arrivals adalah coil saat di stand coil dan kawat di stand kawat untuk proses pengelasan.

\section{d. Resources}

Resources dalam penelitian simulasi ini adalah crane yang berfungsi untuk memindahkan bahan baku pipa yaitu coil dari gudang ke stand coil, memindahkan pipa dari proses pemotongan ke proses bevel dan memindahkan pipa dari proses bevel ke uji hidrostatik.

\section{Relevant System}

Sistem relevan adalah sistem yang mengidentifikasi seluruh komponen relevan, meliputi hubungan struktural dan proses mengenai permasalahan yang dikaji. Pada sistem relevan, dapat diindentifikasikan dalam bentuk wider system dan narrow system [1]. Berikut adalah sistem relevan pada penelitian simulasi ini: 


\section{Dyah Lintang Trenggonowati}

\section{a. Sistem Relevan}

Menggambarkan suatu sistem produksi pipa baja dari penyimpanan bahan baku hingga dipasarkan ke konsumen. Sistem relevan sistem ini adalah wider system dimana sistem dibahas secara menyeluruh. Pada proses yang diberi kotak di dalam kotak proses keseluruhan merupakan narrow system yang peneliti teliti proses produksiya untuk dibuat simulasi.

\section{b. Entity Flow Diagram}

Entity flow diagram menjelaskan aliran entitas dari awal dimulainya proses hingga proses selesai. Entitas awal pada proses produksi pipa tipe AWWA C200 (Pipa Air) adalah coil yang dibeli dari PT. Krakatau Steel dalam bentuk gulungan. Coil tersebut disimpan di gudang dan jika akan mulai diproduksi, coil akan dipindahkan menggunakan crane ke stand coil dimana tempat untuk memulai proses produksi.

Setelah itu, coil yang berbentuk gulungan ditekan serta ditarik maju dan dan mundur menggunakan klem yang berbentuk silinder sehingga menghasilkan coil yang lurus. Klem tersebut mengapit coil yang akan diluruskan dan ditekan sehingga coil tidak akan bergerak. Setelah itu, coil diratakan permukaan sisinya sehingga tidak bergelombang dan akan menghasilkan coil yang permukaannya rata.

Proses selanjutnya adalah proses milling untuk membuat grove pada coil, bisa berbentuk i, x maupun y dan akan menghasilkan coil grove. Selanjutnya adalah proses pre bending, coil grove ditarik menggunakan main drive hingga menekuk dan berputar untuk dilas (bagian dalam dan luar) dengan bantuan kawat las yang disimpan di stand kawat. Keluaran dari hasil las adalah pipa. Namun, pipa ini masih ada proses untuk dapat dipasarkan ke konsumen sebagai pipa kualitas baik.

Pipa yang sudah jadi, akan dilanjutkan dengan proses pemotongan sesuai dengan pesanan konsumen menghasilkan pipa potong. Pipa yang yang sudah dipotong, dipindahkan ke storage sementara. Setelah itu, pipa hasil pemotongan dipindahkan menggunakan crane ke proses bevel untuk merapikan sisi ujung pipa dan dipindahkan menggunakan crane untuk di uji hidrostatik dan bentuk pipa bevel. Fungsi dari uji hidrostatik adalah mengetahui kekuatan pipa dengan tekanan air selama 5 detik sampai mencapai $5 \mathrm{MPa}$ apakah pipa bocor atautidak.

\section{c. Layout Diagram}

Berikut Gambar1 adalah layout diagram proses produksi pipa tipe AWWA (pipa air) C200 yang diteliti:

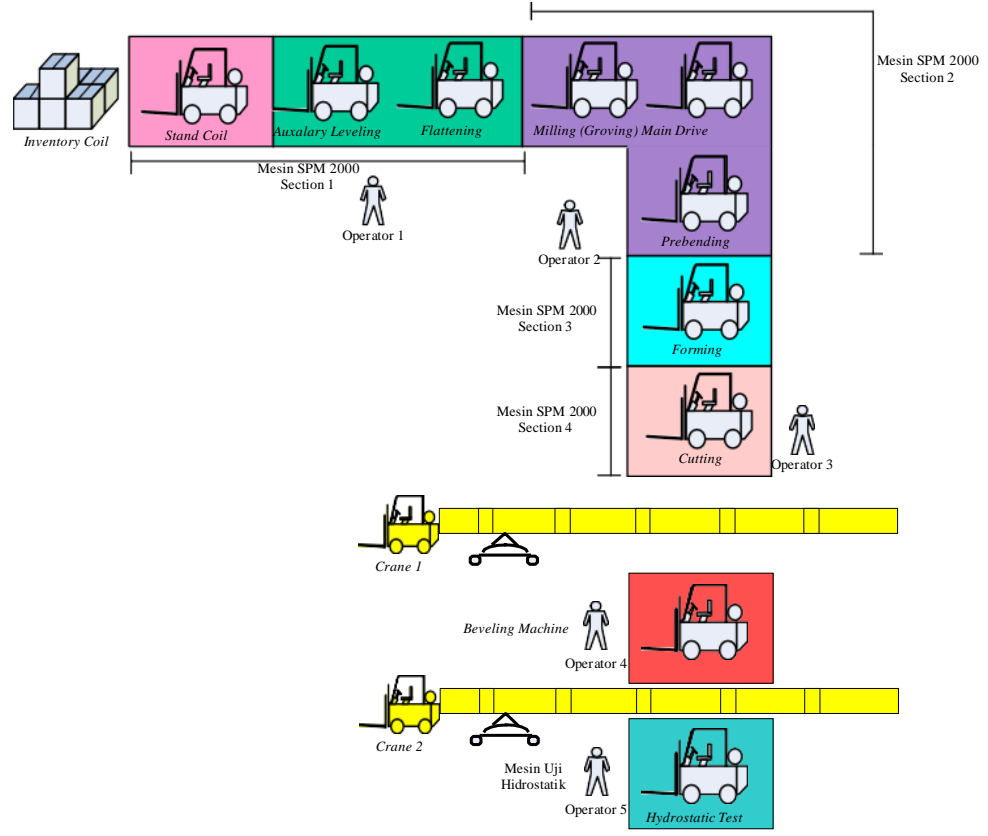

Gambar 1. Layout Diagram 
Gambar 1 menggambarkan layout secara umum proses produksi pipa dari coil menjadi pipa sampai proses uji hidrostatik sesuai dengan batasan penelitian. Layout di atas sesuai dengan alur produksi pipa. Jarak dari gudang ke stand coil adalah $200 \mathrm{~cm}$ dengan pemindahan coil selama 12-15 menit, jarak dari stand coil ke auxalary leveling adalah 50 $\mathrm{cm}$, jarak dari auxalary leveling ke proses flattening adalah $300 \mathrm{~cm}$, jarak dari proses flattening ke proses milling adalah $110 \mathrm{~cm}$, jarak dari proses milling ke alat bantu main drive adalah $190 \mathrm{~cm}$, jarak dari main drive ke proses pre bending adalah $90 \mathrm{~cm}$, jarak dari proses pre bending ke proses forming adalah $289 \mathrm{~cm}$, jarak dari proses forming ke proses pemotongan adalah $780 \mathrm{~cm}$. Setelah pipa diporong, pipa dipindahkan menggunakan crane ke proses bevel dengan jarak $66 \mathrm{~m}$ dan dipindahkan lagi ke proses uji hidrostatik dengan jarak $12,5 \mathrm{~m}$.

Pemindahan coil ataupun pipa menggunakan crane dengan jumlah 1 sampai 2 coil atau pipa sesuai dengan ukurannya. Perpindahan bahan baku dari proses ke proses menggunakan conveyor di dalam mesin sehingga bahan baku akan terus berpindah secara continuous. Crane dan convenyor pun mempunyai kecepatan masing-masing.

\section{Uji Satistika}

PT. KHI Pipe Industries merupakan salah satu anak perusahaan PT. Krakatau Steel Tbk dalam bidang manufaktur yang memproduksi pipa baja. Salah satu jenis pipa yang sering diproduksi adalah pipa air. Dalam proses produksinya, pipa air dengan jenis pipa AWWA C200 menggunakan mesin SPM 2000. Bahan baku utama yang digunakan dalam proses pembuatan pipa adalah coil gulung dan kawat. Coil gulung tiba di stand coil menggunakan distribusi normal dengan waktu rata-rata sebesar 685.767 detik dan standar deviasi 105.708 detik.

Setelah itu, coil gulung akan melalui beberapa proses produksi, seperti proses section 1, proses section 2, proses section 3, proses section 4, proses bevel dan proses hydrostatic test. Coil gulung yang telah tiba di stand coil, kemudian menuju section 1 menggunakan conveyor 1 yang memiliki panjang $3.5 \mathrm{~cm}$ dengan kecepatan $50.5 \mathrm{mpm}$. Perpindahan coil gulung dari conveyor 1 menuju section 1 membutuhkan waktu selama 2 menit. Pada proses section 1, coil gulung diproses menggunakan distribusi lognormal (Tabel 1) dengan waktu rata-rata selama 178.033 detik dan standar deviasi sebesar 25.7474 detik. Proses section 1 merupakan proses auxalary leveling dan flattening dimana coil gulung diluruskan agar permukaannya lurus dan rata.

Setelah terjadi perubahan menjadi coil rata, coil rata menuju section 2 menggunakan conveyor 2 yang memiliki panjang $3.9 \mathrm{~cm}$ dengan kecepatan $50.5 \mathrm{mpm}$. Perpindahan coil flat dari conveyor 2 menuju section 2 membutuhkan waktu selama 3 menit. Proses section 2 yaitu proses milling, main drive dan pre bending. Pada proses ini, semua sisi coil dibuat menjadi grove sebagai bahan lajutan proses pengelasan hingga proses penekukan coil grove untuk dapat memulai proses pengelasan. Proses section 2 ini menggunakan distribusi normal dengan waktu rata-rata 408.067 detik dan standar devisasi 40.6515 detik. Kemudian, coil grove menuju section 3 yaitu proses pengelasan baik pengelasan dalam maupun pengelasan luar dengan menggunakan conveyor 3 yang memiliki panjang $9.89 \mathrm{~cm}$ dan kecepatan 50.5 mpm.

Dalam proses lainnya, kawat las tiba di stand kawat untuk digunakan dalam proses pegelasan. Waktu kedatangan kawat diasumsikan sama dengan waktu kedatangan coil gulung, yaitu menggunakan distribusi normal (Tabel 1) dengan rata-rata waktu sebesar 685.767 detik dan standar deviasi 105.708 detik. Kawat pada stand kawat, juga akan menuju section 3 untuk proses pengelasan pada coil grove sehingga kawat akan melebur menjadi satu dengan coil grove. Coil grove pada conveyor 3 menuju section 3 dengan waktu perpindahan selama 10 menit. Proses section 3 ini menggunakan distribusi 
Industries

\section{Dyah Lintang Trenggonowati}

lognormal (Tabel 1) dengan waktu rata-rata 417.267 detik dan standar deviasi sebesar 86.0673 detik. Setelah proses section 3, coil grove telah berubah menjadi pipa.

Pipa hasil pengelasan akan menuju section 4 (proses pemotongan) menggunakan conveyor 4 dengan panjang $7.8 \mathrm{~cm}$ dan kecepatan $50.5 \mathrm{mpm}$. Perpindahan dari conveyor 4 ke section 4 selama 3 menit. Pada section 3, pipa akan dipotong menjadi 6 pipa. Proses section 4 (proses pemotongan) menggunakan distribusi lognormal (Tabel 1) dengan waktu rata-rata 403.833 detik dan standar deviasi sebesar 122.294 detik

Pipa hasil pemotongan kemudian disimpan di storage sementara dengan waktu perpindahan dari section 4 ke storage sementara selama 5 detik dan pipa akan menunggu dipindahkan ke proses bevel. Perpindahan pipa hasil pemotongan dari storage semetara ke proses bevel menggunakan crane 1. Jarak antar proses tersebut adalah $66 \mathrm{~m}$. Pada proses bevel, pipa hasil pemotongan dirapihkan bagian ujungnya sehingga permukaannya rapi ketika akan disambungkan dengan pipa lainnya sehingga menjadi pipa bevel.

Proses bevel berdistribusi uniform dengan waktu rata-rata sebesar 529.2 detik dan half range sebesar 205.8 detik. Pipa bevel kemudian dipindahkan ke proses hydrostatic test menggunakan crane 2 dengan jarak perpidahan sebesar $12.5 \mathrm{~m}$. Proses hydrostatic test berdistribusi uniform (Tabel 1) dengan waktu rata-rata 216.933 detik dan half range sebesar 67.067 detik. Setiap crane yang digunakan akan kembali ke tempat semula sehingga pergerakan crane dua arah. Kedua crane mempunyai kecepatan yang sama yaitu 25,25 npm baik ketika tidak membawa beban ataupun ketika membawa beban. Proses produksi pipa telah selesai dan diakhiri dengan proses hydrostatic test.

PT. KHI Pipe Indutries hanya memproduksi pipa pada hari Senin sampai hari Jumat. Dalam satu hari terdiri dari 3 shift dengan 7 jam kerja dan 1 jam istirahat. Jadwal shift tersebut berlaku untuk pekerja, mesin (lokasi) dan resources (crane) serta tidak berlaku untuk stand coil, stand kawat dan storage sementara karena meskipun ada jam istirahat, stand coil, stand kawat dan storage sementara akan tetap menyimpan entitasnya masing-masing.

Setelah membuat model konseptual dan mengambil data waktu proses, peneliti melakukan uji statistika untuk mengetahui apakah data layak digunakan untuk simulasi atau tidak. Uji statisika yang dilakukan dalam penelitian simulasi, yaitu uji korelasi, scatter plot, run test, estimasi parameter dan goodness of fit. Berikut Gambar 2 dan Gambar 3 adalah hasil grafik uji korelasi dan scatter plot:
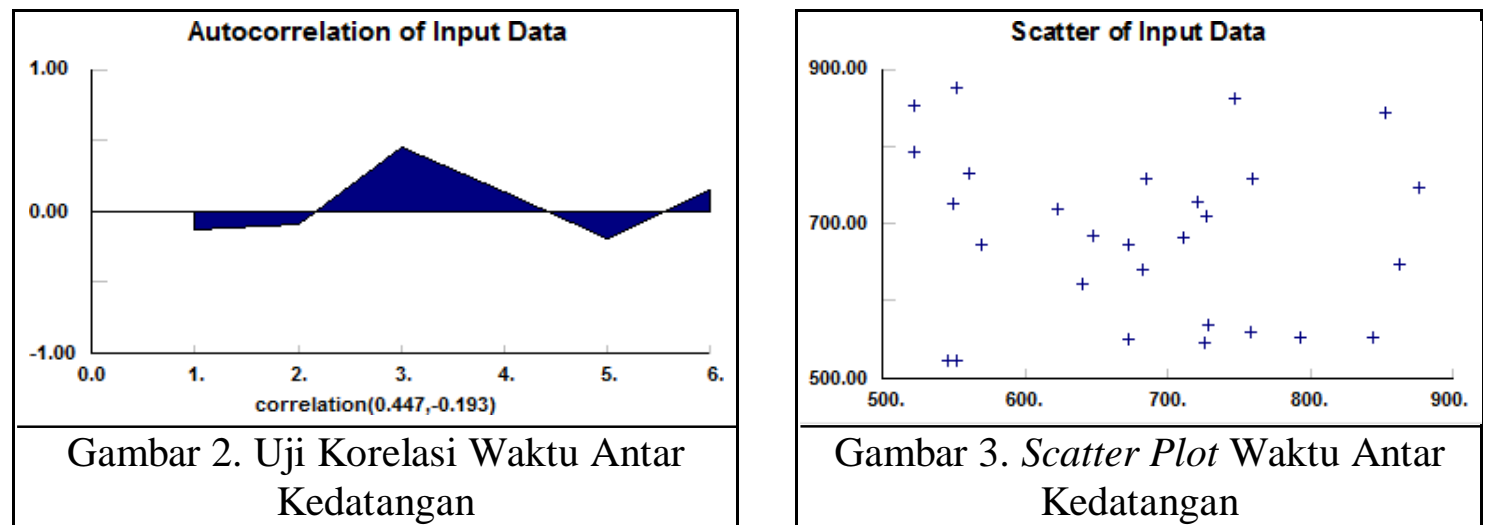

Tabel 1. Hasil Uji Statistika

\begin{tabular}{cllcll}
\hline Waktu & Korelasi & Scatter Plot & Run Test & Estimasi Parameter & Goodnes offit \\
\hline Waktu Antar & Tidak berkolerasi & Data independen & Data don't reject & Distribusi Normal & Distribusi don't reject \\
Kedatangan & Tidak berkolerasi & Data independen & Data don't reject & Distribusi Lognormal & Distribusi don't reject \\
Proses Section 1 & Tidak berkolerasi & Data independen & Data don't reject & Distribusi Normal & Distribusi don't reject \\
Proses Section 2 & Tidak berkolerasi & Data independen & Data don't reject & Distribusi Normal & Distribusi don't reject \\
Proses Section 3 & Tidak berkolerasi & Data independen & Data don't reject & Distribusi Lognormal & Distribusi don't reject \\
Proses Section 4 & Tidak berkolerasi & Data independen & Data don't reject & Distribusi Uniform & Distribusi don't reject \\
Bevel & Tidak berkolerasi & Data independen & Data don't reject & Distribusi Uniform & Distribusi don't reject \\
Hydrostatic Test & & & &
\end{tabular}


Berdasarkan pengujian menggunakan Autofit Software Pro Model 7.5, data yang peneliti ambil untuk melakukan simulasi layak untuk digunakan. Hasil data tersebut telah tercantum dalam Gambar 2 dan Gambar 3. Hasil uji korelasi, grafik memiliki data yang berada pada dua sisi yaitu positif dan negatif. Hal ini menunjukkan bahwa data tidak berkolerasi. Hasil uji scatter plot pun menyatakan data independen dan random, karena data tersebar dan tidak berkumpul di beberapa titik saja, data juga tidak menunjukkan pola tertentu sehingga data dikatakan layak digunakan [2]. Tabel 1 adalah hasil rekapan dari uji statistika untuk setiap waktu proses.

Hasil run test, data independen (saling tidak berkaitan antara satu data dengan data yang lain), random (acak atau menyebar) dan data cukup sehingga data layak untuk digunakan. Estimasi parameter untuk memutuskan bentuk distribusi dari data yang dimiliki dengan penerimaannya harus "do not reject". Goodness of fit merupakan uji statistik untuk menguji apakah distribusi probabilitas terpilih benar-benar tepat mewakili sampel data dan berdasarkan hasil goodness of fit, distribusi yang telah terpilih benar-benar dapat digunakan.

\section{PENGEMBANGAN MODEL DAN ANALISIS}

Perancangan model simulasi eksisting dimulai dengan perancangan model konseptual, penentuan asumsi model dan penentuan distribusi data menggunakan statfit untuk mengetahui jenis distribusi yang mewakili data yang digunakan. Pada model ini, proses dimulai dari guang bahan baku coil menuju stand coil sebagai tempat awal proses pembuatan pipa dan akan terus melakukan proses produksi pada section 1, section 2, section 3 , section 4, bevel dan hydrostatic test, yang digambarkan pada Gambar 4.

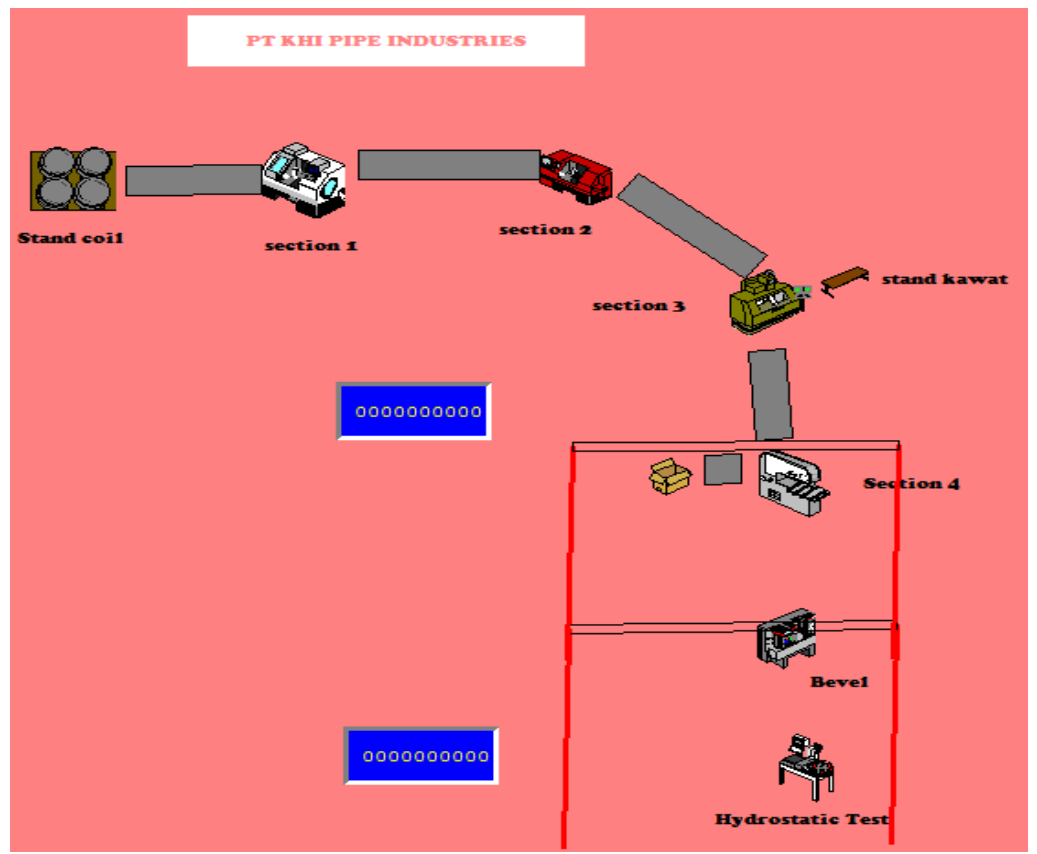

Gambar 4. Layout Model Existing

\section{Replikasi dan Validitas Model Awal}

Replikasi awal yang dilakukan $n$ kali dimana $n \geq 5$ [2]. Pada penelitian ini, peneliti melakukan sebanyak 10 replikasi sebagai replikasi awal dengan waktu untuk satu kali replikasi selama 21 jam. Replication digunakan untuk menggambarkan perilaku random/ probabilistic dari suatu sistem. Berdasarkan perhitungan di atas maka jumlah replikasi yang dibutuhkan sebanyak 8 replikasi $\left(\mathrm{N}^{\prime}<\mathrm{N}\right.$, yaitu $\left.8<10\right)$, sehingga dapat disimpulkan bahwa dengan jumlah replikasi awal sebanyak 10 replikasi telah mencukupi replikasi minimal yang dibutuhkan (Tabel 2). 
Dyah Lintang Trenggonowati

Tabel 2. Perhitungan Replikasi

\begin{tabular}{ccccccc}
\hline No & Xi & $\bar{X}$ & $(\mathrm{Xi}-\bar{X})^{2}$ & S & Error & N' $^{\prime}$ \\
\hline 1 & 2242 & & 136.89 & & & \\
2 & 2256 & 2253.7 & 5.29 & & & \\
3 & 2259 & & 28.09 & & & \\
4 & 2259 & & 28.9 & & & \\
5 & 2257 & & 10.89 & 9.1657575 & 6.5563324 & 7.5080463 \\
6 & 2247 & & 44.89 & & & \\
7 & 2237 & 278.89 & & & \\
8 & 2262 & & 68.89 & & & \\
9 & 2252 & & 2.89 & & \\
10 & 2266 & & 151.29 & & \\
\hline Total & $\mathbf{2 2 5 3 7}$ & $\mathbf{5 9 6 . 5}$ & & & \\
\hline
\end{tabular}

Hasil dari Tabel 2, kemudian dilakukan perhitungan untuk menentukan jumlah replikasi minimum yang diperlukan, berikut perhitungannya:

$$
\begin{aligned}
\bar{X} & =\frac{\sum x_{i}}{n} & & \left(t_{n-1, \frac{\alpha}{2}}\right) s \\
& =\frac{22537}{10} & & =\frac{(2.262) 9.1657575}{\sqrt{10}} \\
& =2253.7 & & =6.5563324 \\
S & =\sqrt{\frac{\sum\left(X_{i}-\bar{X}\right)^{2}}{n-1}} & n^{\prime} & =\left[\frac{\left(z_{\alpha / 2}\right) s}{\left(\frac{r e}{(1+r e)}\right) \bar{x}}\right]^{2} \\
& =\sqrt{\frac{596.5}{10-1}} & & =7,5080463 \approx 8 \\
& =9.1657575 & &
\end{aligned}
$$

Validasi adalah penentuan apakah model konseptual simulasi (sebagai tandingan program komputer) adalah representasi akurat dari sistem nyata yang sedang dimodelkan [2]. Metode yang digunakan untuk menguji validitas hasil output (Tabel 3) simulasi eksisting adalah dengan uji hipotesis dua rata-rata. Uji hipotesis dua rata-rata digunakan untuk mengetahui ada atau tidak adanya perbedaan (kesamaan) antara dua buah data. Teknik analisis statistik untuk menguji hipotesis dua rata-rata ini ialah paired sample t-test (Tabel 4) [3],[4] dimana tahapan pertama pengujian ini untuk mengetahui bahwa varian kedua kelompok adalah sama atau tidak, berikut hipotesisnya:

$$
\begin{aligned}
& \mathrm{H}_{0}: \mu_{1}=\mu_{2} \\
& \mathrm{H}_{1}: \mu_{1} \neq \mu_{2}
\end{aligned}
$$

Tabel 3. Data Output Sistem Nyata dan Sistem Simulasi

\begin{tabular}{ccc} 
Replikasi & $\begin{array}{c}\text { Output Sistem Nyata } \\
\text { (Unit) }\end{array}$ & $\begin{array}{c}\text { Output Sistem Simulasi } \\
\text { (Unit) }\end{array}$ \\
\hline 1 & 2276 & 2242 \\
2 & 2247 & 2256 \\
3 & 2228 & 2259 \\
4 & 2246 & 2259 \\
5 & 2264 & 2257 \\
6 & 2209 & 2247 \\
7 & 2228 & 2237 \\
8 & 2280 & 2262 \\
9 & 2260 & 2252 \\
10 & 2271 & 2266 \\
\hline Total & 22509 & 22537 \\
\hline Mean & 2250.9 & 2253.7 \\
\hline
\end{tabular}

Dari hasil output model eksisting dengan replikasi awal $n=10$, diperoleh data sebagai berikut (Tabel 4 dan Tabel 5): 
Tabel 4. Paired Sample Statistics

\begin{tabular}{|ll|r|r|r|c|}
\hline & & \multicolumn{1}{|c|}{ Mean } & \multicolumn{1}{c|}{ N } & Std. Deviation & $\begin{array}{c}\text { Std. Error } \\
\text { Mean }\end{array}$ \\
\hline Pair1 & Nyata & 2250.9000 & 10 & 23.52044 & 7.43782 \\
& Simulasi & 2253.7000 & 10 & 9.16576 & 2.89847 \\
\hline
\end{tabular}

Tabel 5. Paired Samples Correlations

\begin{tabular}{|c|c|c|c|}
\hline & $\mathrm{N}$ & Correlation & Sig. \\
\hline Pair $1 \quad$ Nyata \& Simulasi & 10 & .376 & .284 \\
\hline
\end{tabular}

Tabel 6. Paired Samples Test

\begin{tabular}{|c|c|c|c|c|c|c|c|c|}
\hline & \multicolumn{5}{|c|}{ Paired Differences } & \multirow[b]{3}{*}{$t$} & \multirow[b]{3}{*}{ df } & \\
\hline & \multirow[b]{2}{*}{ Mean } & \multirow[b]{2}{*}{ Std. Deviation } & \multirow{2}{*}{$\begin{array}{l}\text { Std. Error } \\
\text { Mean }\end{array}$} & \multicolumn{2}{|c|}{$\begin{array}{l}\text { 95\% Confidence Interval of the } \\
\text { Difference }\end{array}$} & & & \multirow[b]{2}{*}{ Sig. (2-tailed) } \\
\hline & & & & Lower & Upper & & & \\
\hline Pair 1 Nyata - Simulasi & -2.80000 & 21.79602 & 6.89251 & -18.39194 & 12.79194 & -.406 & 9 & 694 \\
\hline
\end{tabular}

Untuk melihat suatu data dapat dinyatakan valid atau tidak valid pada Tabel 6, dapat dilakukan dengan 3 pengujian, yaitu melihat nilai kritis data, uji t dan $p$-value. Jika dilihat dari nilai kritis, nilai rata-rata (mean) masuk dalam rentang lower bound dan upper bound. Selain, data tersebut menunjukkan paired differenece melewati 0 sehingga $\mathrm{H}_{0}$ diterima yang artinya tidak ada perbedaan yang significant antara sistem nyata dan sistem simulasi.

Jika dilihat dari uji $t$, $t_{\text {hitung }}$ yang didapat adalah -0.096 sedangkan $t_{\text {tabel }}(0.05,9)$ adalah 2.262. Hasil tersebut menyatakan bahwa $t_{\text {hitung }}<t_{\text {tabel }}$ sehingga $\mathrm{H}_{0}$ diterima. $\mathrm{H}_{0}$ diterima artinya tidak ada perbedaan yang significant antara sistem nyata dan sistem simulasi. Alternatif ketiga untuk melihat hasil validasi adalah $p$-value. Nilai Sig (2-tailed) $>\alpha$ dimana $0.694>0.05$ yang menyatakan bahwa $\mathrm{H}_{0}$ diterima. $\mathrm{H}_{0}$ diterima artinya tidak ada perbedaan yang significant antara sistem nyata dan sistem simulasi (output sistem nyata sama dengan output sistem simulasi). Berdasarkan tiga pengujian tersebut, maka data dinyatakan valid [3],[4].

\section{Perancangan Model Usulan Perbaikan}

Setelah mevalidasi model tersebut dan mendapatkan output dari model eksisting, langkah selanjutnya adalah merancang usulan perbaikan. Perancangan usulan perbaikan bertujuan untuk memperbaiki sistem konseptual yang ada. Penelitian ini bertujuan untuk meningkatkan produktivias pipa air tipe AWWA 200. Oleh karena itu, perancangan usulan perbaikan yang dibuat akan fokus pada perbaikan produktivitas pipa air tipe AWWA 200. Beberapa usulan perbaikan (Tabel 7) yang peneliti lakukan adalah (1) Penambahan mesin bevel dan mesin hydrostactic test menjadi dua dan menambah crane, (2) Penambahan mesin bevel, mesin hydrostactic test dan section satu menjadi dua dan menambah crane, dan (3) Penambahan mesin bevel, mesin hydrostactic test dan section dua menjadi dua dan menambah crane.

Tabel 7. Data Output Sistem Tiap Usulan perbaikan

\begin{tabular}{cccccc}
\hline Replikasi & $\begin{array}{c}\text { Output } \\
\text { Eksisting } \\
\text { (Unit) }\end{array}$ & $\begin{array}{c}\text { Output Usulan } \\
\text { perbaikan 1 } \\
\text { (Unit) }\end{array}$ & $\begin{array}{c}\text { Output Usulan } \\
\text { perbaikan 2 (Unit) }\end{array}$ & $\begin{array}{c}\text { Output Usulan } \\
\text { perbaikan 3 (Unit) }\end{array}$ & Total \\
\hline 1 & 2242 & 4797 & 4791 & 4765 & 16595 \\
2 & 2256 & 4798 & 4781 & 4800 & 16635 \\
3 & 2259 & 4817 & 4798 & 4774 & 16648 \\
4 & 2259 & 4807 & 4788 & 4799 & 16653 \\
5 & 2257 & 4789 & 4796 & 4806 & 16648 \\
6 & 2247 & 4766 & 4799 & 4735 & 16547 \\
7 & 2237 & 4790 & 4779 & 4779 & 16585 \\
8 & 2262 & 4768 & 4800 & 4803 & 16633 \\
9 & 2252 & 4763 & 4789 & 4764 & 16568 \\
10 & 2266 & 4766 & 4798 & 4811 & 16641 \\
\hline Jumlah & 22537 & 47861 & 47919 & 47836 & 166153 \\
\hline
\end{tabular}


Berdasarkan hasil output tersebut selanjutnya akan dilakukan pengujian ANOVA. Analisis varians (Analysis of Variance - ANOVA) adalah prosedur statistika untuk mengkaji (mendeterminasi) apakah rata-rata hitung (mean) dari 3 (tiga) populasi atau lebih, sama atau tidak. Berdasarkan hasil perhitungan ANOVA pada Tabel 8, didapatkan nilia $F_{\text {hitung }}$ sebesar 58009.93681 sedangkan $\mathrm{F}_{\text {tabel }}$ dari distibusi $\mathrm{F}(0.05 ; 3 ; 36)=2.84$.

Dengan demikian, $F_{\text {hitung }}>\mathrm{F}_{\text {tabel }}$ yaitu $79892.6816>2.84$. Dengan nilai tersebut, dapat disimpulkan bahwa Ho ditolak yang berarti bahwa model eksisting, usulan perbaikan 1, usulan perbaikan 2 dan usulan perbaikan 3 mempunyai perbedaan yang significant. Dengan kata lain, paling tidak ada satu model usulan perbaikan yang mempunyai perbedaan dengan model eksisting. Oleh karena itu, usulan perbaikan yang dibuat layak untuk dibandingkan.

Tabel 8. Hasil Uji Anova dengan Software SPSS 20 ANOVA

Usulan_Perbaikan
\begin{tabular}{|l|r|r|r|r|c|}
\hline & \multicolumn{1}{c|}{$\begin{array}{c}\text { Sum of } \\
\text { Squares }\end{array}$} & \multicolumn{1}{c|}{ df } & Mean Square & F & \multicolumn{1}{c|}{ Sig. } \\
\hline Between Groups & 48140029.48 & 3 & 16046676.49 & 58009.937 & .000 \\
Within Groups & 9958.300 & 36 & 276.619 & & \\
Total & 48149987.78 & 39 & & & \\
\hline
\end{tabular}

Pada hasil pengujian ANOVA pada Tabel 8 tidak diketahui apa saja yang berbeda dan bagaimana perbedaan yang ada, maka dari itu dilakukan post-hoc test dengan menggunakan LSD (Least Significant Difference) untuk mengetahui apa saja yang berbeda dan bagaimana perbedaan yang ada. Dan hasilnya dapat terlihat pada tabel di bawah ini.

Tabel 9. Hasil Uji LSD Post Hoc dengan Software SPSS 20 Post Hoc Tests

\begin{tabular}{|c|c|c|c|c|c|c|}
\hline \multicolumn{7}{|c|}{ Multiple Comparisons } \\
\hline \multicolumn{7}{|c|}{$\begin{array}{l}\text { Dependent Variable: Usulan_Perbaikan } \\
\text { LSD }\end{array}$} \\
\hline \multirow[b]{2}{*}{ (1) Kondisi } & \multirow[b]{2}{*}{ (J) Kondisi } & \multirow{2}{*}{$\begin{array}{c}\text { Mean } \\
\text { Difference (l- } \\
\mathrm{J})\end{array}$} & \multirow[b]{2}{*}{ Std. Error } & \multirow[b]{2}{*}{ Sig. } & \multicolumn{2}{|c|}{$95 \%$ Confidence Interval } \\
\hline & & & & & Lower Bound & Upper Bound \\
\hline \multirow[t]{3}{*}{ Eksisting } & Usulan_Perbaikan1 & $-2532.400^{\prime}$ & 7.438 & .000 & -2547.48 & -2517.32 \\
\hline & Usulan_Perbaikan2 & $-2538.200^{*}$ & 7.438 & .000 & -2553.28 & -2523.12 \\
\hline & Usulan_Perbaikan3 & $-2529.900^{*}$ & 7.438 & .000 & -2544.98 & -2514.82 \\
\hline \multirow[t]{3}{*}{ Usulan_Perbaikan1 } & Eksisting & $2532.400^{\prime}$ & 7.438 & .000 & 2517.32 & 2547.48 \\
\hline & Usulan_Perbaikan2 & -5.800 & 7.438 & .441 & -20.88 & 9.28 \\
\hline & Usulan_Perbaikan3 & 2.500 & 7.438 & .739 & -12.58 & 17.58 \\
\hline \multirow[t]{3}{*}{ Usulan_Perbaikan2 } & Eksisting & $2538.200^{n}$ & 7.438 & .000 & 2523.12 & 2553.28 \\
\hline & Usulan_Perbaikan1 & 5.800 & 7.438 & .441 & -9.28 & 20.88 \\
\hline & Usulan_Perbaikan3 & 8.300 & 7.438 & .272 & -6.78 & 23.38 \\
\hline \multirow[t]{3}{*}{ Usulan_Perbaikan3 } & Eksisting & $2529.900^{n}$ & 7.438 & .000 & 2514.82 & 2544.98 \\
\hline & Usulan_Perbaikan1 & -2.500 & 7.438 & .739 & -17.58 & 12.58 \\
\hline & Usulan_Perbaikan2 & -8.300 & 7.438 & .272 & -23.38 & 6.78 \\
\hline
\end{tabular}

Berdasarkan hasil uji posc hoc menggunakan LSD pada Tabel 9, dapat diperoleh perbandingan antara model existing dengan model usulan perbaikan 1 adalah signifikan perbedaannya, hal ini dapat dilihat dari perhitungan $\mu_{1}$ dan $\mu_{2}$ yang tidak melewati 0 yaitu $2547,48 \leq \mu_{1-} \mu_{2} \leq-2517,32$. Hal tersebut berarti penolakan $\mathrm{H}_{0}$ dengan kata lain kedua model tersebut berbeda. 
Berdasarkan hasil uji posc hoc menggunakan LSD dapat diperoleh perbandingan antara model existing dengan model usulan perbaikan 2 adalah signifikan perbedaannya, hal ini dapat dilihat dari perhitungan $\mu_{1}$ dan $\mu_{2}$ yang tidak melewati 0 yaitu $-2553,28 \leq \mu_{1}$. $\mu_{2} \leq-2523,12$. Hal tersebut berarti penolakan $\mathrm{H}_{0}$ dengan kata lain kedua model tersebut berbeda.

Berdasarkan hasil uji posc hoc menggunakan LSD dapat diperoleh perbandingan antara model existing dengan model usulan perbaikan 3 adalah signifikan perbedaannya, hal ini dapat dilihat dari perhitungan $\mu_{1}$ dan $\mu_{2}$ yang tidak melewati 0 yaitu $-2544,98 \leq \mu_{1}$ $\mu_{2} \leq-2514,82$. Hal tersebut berarti penolakan $\mathrm{H}_{0}$ dengan kata lain kedua model tersebut berbeda [5].

Tabel 10. Pemilihan Usulan Perbaikan Terbaik

\begin{tabular}{cc}
\hline Kondisi & Rata-rata Output (Unit) \\
\hline Usulan perbaikan 2 & 4791 \\
Usulan perbaikan 1 & 4786 \\
Usulan perbaikan 3 & 4783 \\
Existing & 2253 \\
\hline
\end{tabular}

Usulan perbaikan yang dipilih adalah usulan perbaikan dengan rata-rata unit tertinggi. Dari Tabel 10. didapatkan usulan perbaikan 2 adalah usulan perbaikan dengan rata-rata unit produksi tertinggi. Hal ini mengindikasikan bahwa usulan perbaikan 2 merupakan pilihan rekomendasi terbaik untuk meningkatkan produktifitas di PT. KHI Pipe Industries.

\section{KESIMPULAN}

Berdasarkan pengamatan dan pengolahan data yang telah dilakukan di PT. KHI Pipe Industries dapat diperoleh kesimpulan sebagai berikut:

1. Jumlah rata-rata produk pipa yang dihasilkan pada simulasi sistem eksisting produksi pipa baja las spiral yaitu 2253 unit per bulan.

2. Alternatif perbaikan pada proses produksi dilakukan agar produksi pipa baja las spiral dapat meningkat dari keadaaan eksisting yaitu usulan perbaikan 1 dengan menambahkan bevel machine dan hydrostatic test machine menjadi dua unit serta menambahkan crane menjadi dua unit untuk perpindahan dari storage sementara ke bevel dan dari bevel ke hydrostatic test, usulan perbaikan 2 dengan menambahan mesin di section 1, bevel machine dan hydrostatic test machine menjadi dua unit serta menambahkan crane menjadi dua unit untuk perpindahan dari storage sementara ke bevel dan dari bevel ke hydrostatic test, usulan perbaikan 3 dengan menambahkan mesin di section 2, bevel machine dan hydrostatic test machine menjadi dua unit serta menambahkan crane menjadi dua unit untuk perpindahan dari storage sementara ke bevel dan dari bevel ke hydrostatic test.

3. Jumlah rata-rata produk pipa baja las spiral optimal yang dihasilkan pada alternatif perbaikan terpilih yaitu usulan perbaikan 2 dengan menambahkan mesin di section 1 , bevel machine dan hydrostatic test machine menjadi dua unit serta menambahkan crane menjadi dua unit untuk perpindahan dari storage sementara ke bevel dan dari bevel ke hydrostatic test yaitu 4791 unit per bulan.

\section{DAFTAR PUSTAKA}

[1]. Harrell C., 2003, Simulation Using Promodel. McGRaw-Hill, New York.

[2]. Law A., 2006, Simulation Modeling and Analysis with Expertfit Software. McGRawHill, New York. 
Dyah Lintang Trenggonowati

[3]. Trenggonowati, D.L., 2015, Optimasi Proses Produksi dengan Mengunakan Pendekatan Simulasi Sistem. Jurnal PASTI, Volume XI No. 1, 1-12.

[4]. Trenggonowati, D.L., 2017, Simulation System Optimize The Time Of Process. Jurnal Performa, Vol. 16 No. 2 Hal 134-142.

[5]. Daellenbach, H.G. 1994 System and Decision Making: A Management Science Approach. Chichester: John Wiley \& Sons, Ltd. 